\title{
Automated Continuous Measurement of Erythrocyte Volume under Isotonic Conditions
}

\author{
Noriyuki Tatsumi, Izumi Tsuda, Hiroaki MaEda, \\ and Hideaki Matsumoto \\ Department of Clinical Medicine, Osaka City University Medical School, \\ Osaka, Osaka, 545 Japan
}

\begin{abstract}
The time course of volume changes of erythrocytes, suspended in isotonic solutions containing permeable substances, was studied using a cell monitoring system which was assembled on the basis of Coulter's principle. For comparison, the hematocrit method was employed. The data obtained demonstrated that urea, glycerol, ethanol, and methanol induced a rapid volume increase, whereas glucose and galactose induced a slow volume increase. These results correspond well to the data obtained by the hematocrit method. The present method, which requires only a minimum volume of blood, showed high accuracy and high reproducibility. Thus, the method was considered applicable to experimental and clinical studies of membrane permeability of erythrocytes.
\end{abstract}

Key Words: volume-change curve, erythrocytes, glucose, galactose.

It is well known that erythrocyte volume changes when permeable substances move across the cell membrane along a concentration gradient under isotonic conditions (MACKNIGHT and LeAF 1977; GotTFRIED and RoBertson, 1972; De GIER et al., 1966; WeSSELS and VEERKAMP, 1973). The permeability of a particular substance has usually been assessed by measuring the uptake rate of radioisotopes (ZIPPER and MAWE, 1974), qualitative changes of the constituents (LEVINE and Stern, 1966), photometric changes of the cell suspension (PARPART, 1935), or hematocrit changes (UeSAKA and ShInAGawa, 1979). Since such methods were technically difficult and time consuming, they could not be applied for clinical purposes. Furthermore, there are limitations in their ability to measure rapid volume changes accompanied by the permeation of substances across the membrane within a short period of time.

In most hematology laboratories, the cell volume is usually determined by a method based on Coulter's principle (MATtERn, et al., 1957). Although such a

Received for publication August 17, 1983

巽 典之, 津田 泉, 前田宏明, 松本英彬 
method can be usefully applied to determine cell volume under fixed conditions with a small amount of blood, it is unable to measure volume accurately in solutions with different electric conductivities. In this study, a new type of instrument, capable of continuously measuring the cell volume at different conductivities, was introduced for estimating the changes in cell volume induced by permeation of low molecular weight substances such as urea, glycerol, ethanol, methanol, and hexoses.

\section{MATERIALS AND METHODS}

1. Blood specimens. Venous blood anticoagulated with EDTA was obtained from healthy donors. Before each experiment, mean cell volume (MCV) of each sample was first determined using Coulter's blood cell counter (Coulter SP-II, USA).

2. Determination principle. A Continuous MCV Analyzer System (CMA, TOA Medical Electronics Co.; Kobe-Los Angeles-Hamburg) was used for determining the time course of volume changes (Fig. 1). The CMA is a computerized version of the Continuous MCV Counter (CMC; TOA Medical Electronics Co.) (TATSUmi, 1981; TATSUmi et al., 1981). In this apparatus, the resistance pulse produced by a particle of a given volume passing through a Coulter-type aperture is reduced, assuming that the electric field is uniform and that the introduction of a particle in the orifice does not alter the structure of the field in any other part of the orifice occupied by the particle. With these assumptions, the following equation is obtained:

$$
V_{\mathrm{p}}=A^{2} /\left\{r_{\mathrm{o}} \times d R \times f(a)\right\},
$$

where $a$ is the ratio of the maximum cross section of the particle perpendicular to the axis of the orifice, to the cross section $A\left(\mathrm{~m}^{2}\right)$ of the orifice, $V_{\mathrm{p}}\left(\mathrm{m}^{3}\right)$ is the volume of the particle, $r_{\mathrm{o}}(\Omega \mathrm{m})$ is the resistivity of the electrolyte, $d R(\Omega)$ is the resistance pulse amplitude, and $f(a)$ is a correlation factor (ECKHOFF, 1969). If particles with a uniform volume are suspended in solutions with different resistivity, the $V_{\mathrm{p}}$ values change with the resistivity of solution. When an appropriate $f(a)$ is determined, the correct $V_{\mathrm{p}}$ value is obtained. In CMA, the $f(a)$ is set empirically using standard resin particles of various size (The Dow Chemical Co., Indianapolis) in each experimental solution and the empirical $f(a)$ is manually input into the analyzer to get corrected volume values. A high correlation is observed between the calibrated values by CMA for standard resins and the catalogue values $(r>0.99)$. The analyzer unit stores all determined values and displays the data as a time-serial curve on a cathode-ray tube. The temperature of erythrocyte suspension is kept constant using a thermo-regulation unit and a stirrer. The electric conductivity of the sample solution is maintained with isotonic saline $(0.154$ $\mathrm{M}$, osmolality $285.0 \mathrm{mOsm} / \mathrm{kg}$ ). 


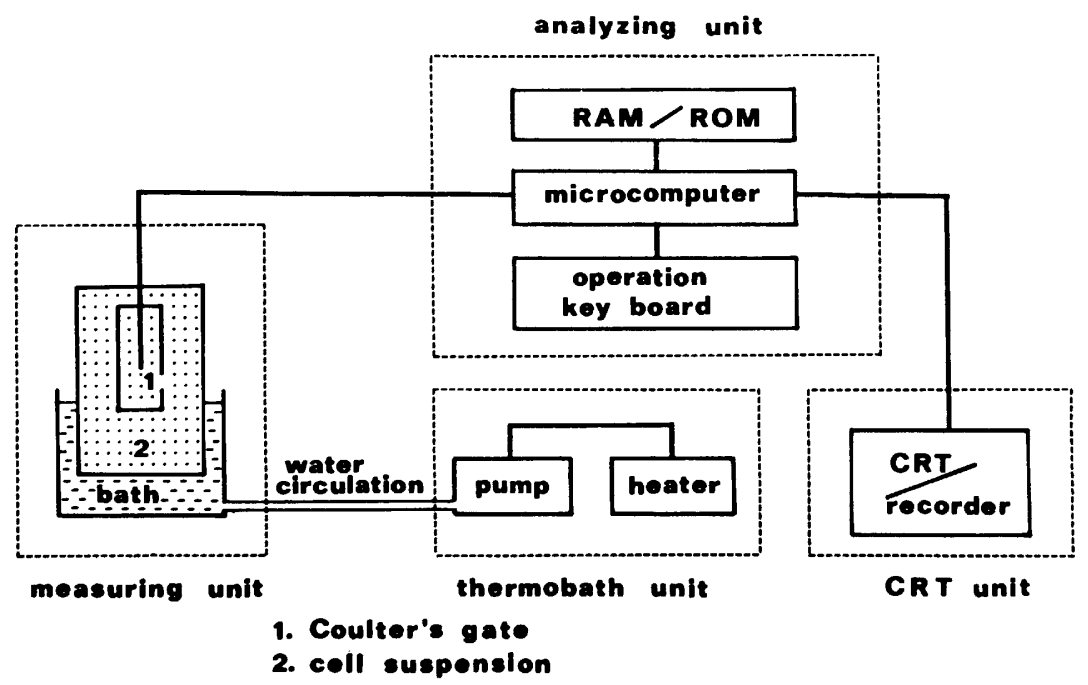

Fig. 1. Block diagram of the Continuous MCV Analyzer (CMA).

3. Experimental procedures. Blood $(2 \mu 1)$ was suspended in a mixture (50 $\mathrm{ml}$ ) of isotonic solution of a test substance and saline containing $1 \mathrm{~mm}$ sodium phosphate buffer ( $\mathrm{pH}$ 7.4). Immediately after setting the suspension in the counter, the continuous measurement of MCV was started. The determined values were recorded every $2 \mathrm{sec}$, and after 100 determinations the changes in MCV were plotted as a function of time $(\mathrm{sec})$. All measurements were carried out at $30^{\circ} \mathrm{C}$.

4. Osmolality. Osmolality of the suspending medium was adjusted to $285 \pm 10 \mathrm{mOsM} / \mathrm{kg} \mathrm{H}_{2} \mathrm{O}\left(30^{\circ} \mathrm{C}\right)$. The osmolality was determined with an Osmostat (Kyoto Daiichi Kagaku Co., Kyoto).

5. Scanning electron microscopy. Cells in an isotonic condition were examined by scanning electron microscopy according to the method of Hattori (HATTORI et al., 1975).

6. Hematocrit determination. Hematocrit was measured using a capillary tube (Surgicot, New York) according to the standard microhematocrit method (ARCHER et al., 1982).

7. Chemicals. All chemicals were purchased from Sigma Chemicals (St. Louis).

\section{RESULTS}

1. Changes of erythrocyte volume in isotonic mixtures of several low molecular weight substances

The figures drawn by the CMA are shown in Figs. 2 and 3. Standard resin 

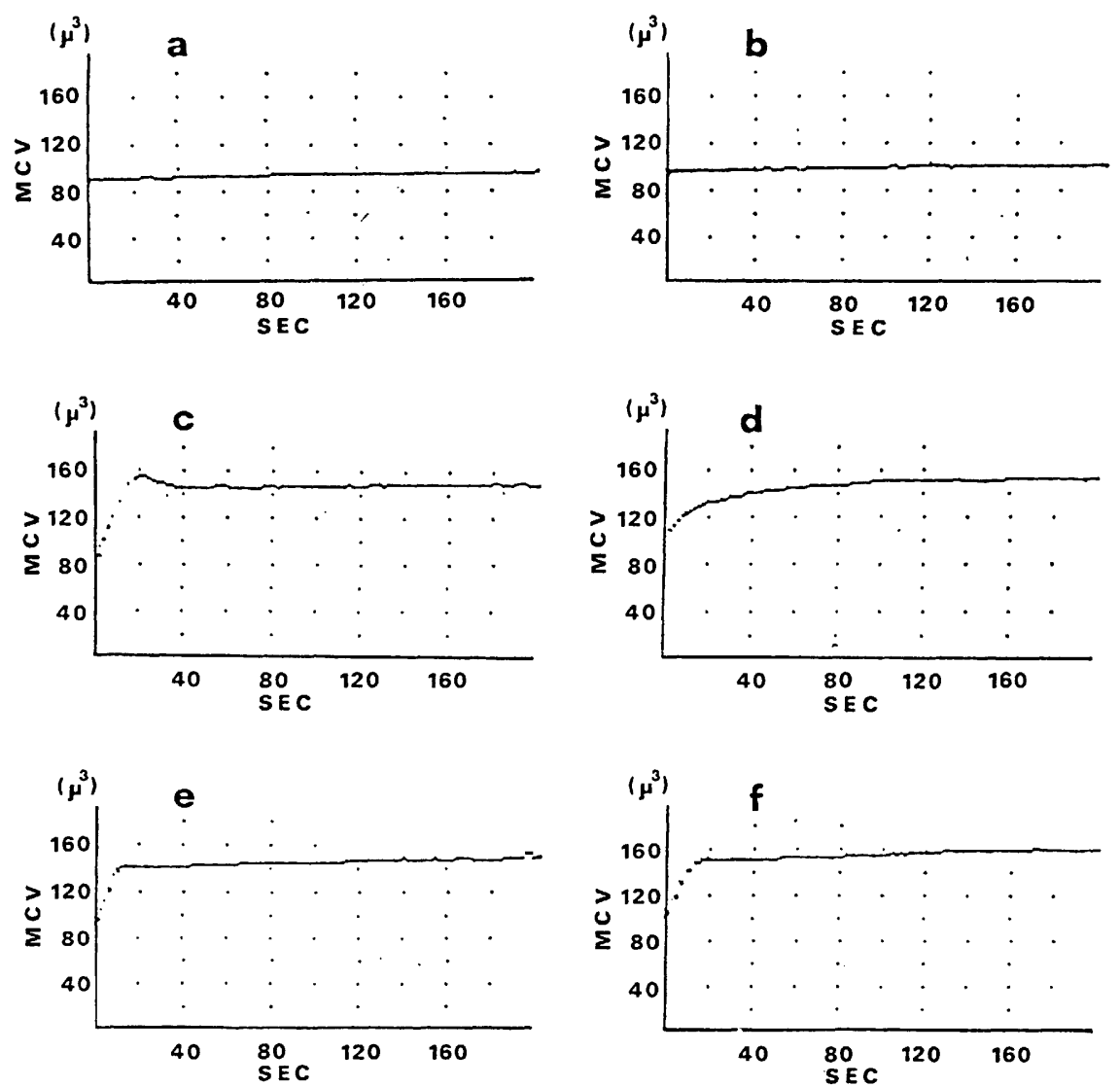

Fig. 2. Traces of MCV changes measured by CMA. Volume of erythrocyte in saline mixed without (a) or with other isotonic solutions, such as sucrose (b), urea (c), glycerol (d), methanol (e), or ethanol (f). The mixing ratio of saline and each solution is $3 \mathrm{vol}: 2$ vol. Final concentrations of these mixtures are (b) $0.11 \mathrm{M}$, (c) $0.11 \mathrm{M}$, (d) $0.10 \mathrm{M}$, (e) $0.22 \mathrm{M}$, and (f) $0.15 \mathrm{M}$. Slight increases in cell volume are seen in (a) and (b), whereas significantly large increases are seen in (c) to (f).

particles showed no volume changes in any tested media with a coefficient of variation $(\mathrm{CV})$ of $0.4 \%$ in 100 determinations. In a saline solution or in a mixture of sucrose solution and saline, the cell volume showed no significant change (Fig. $2 a, b)$.

In mixtures of low molecular weight substances and saline, erythrocytes showed marked volume changes. In a mixture of isotonic urea solution and saline, the cell volume rapidly increased and then decreased (Fig. 2c).

In a mixture of isotonic glycerol and saline solution, the volume increased gradually to an equilibrated volume (Fig. 2d), while in a mixture of isotonic methanol or ethanol and saline, it increased rapidly (Fig. 2e, f). The CMA could 

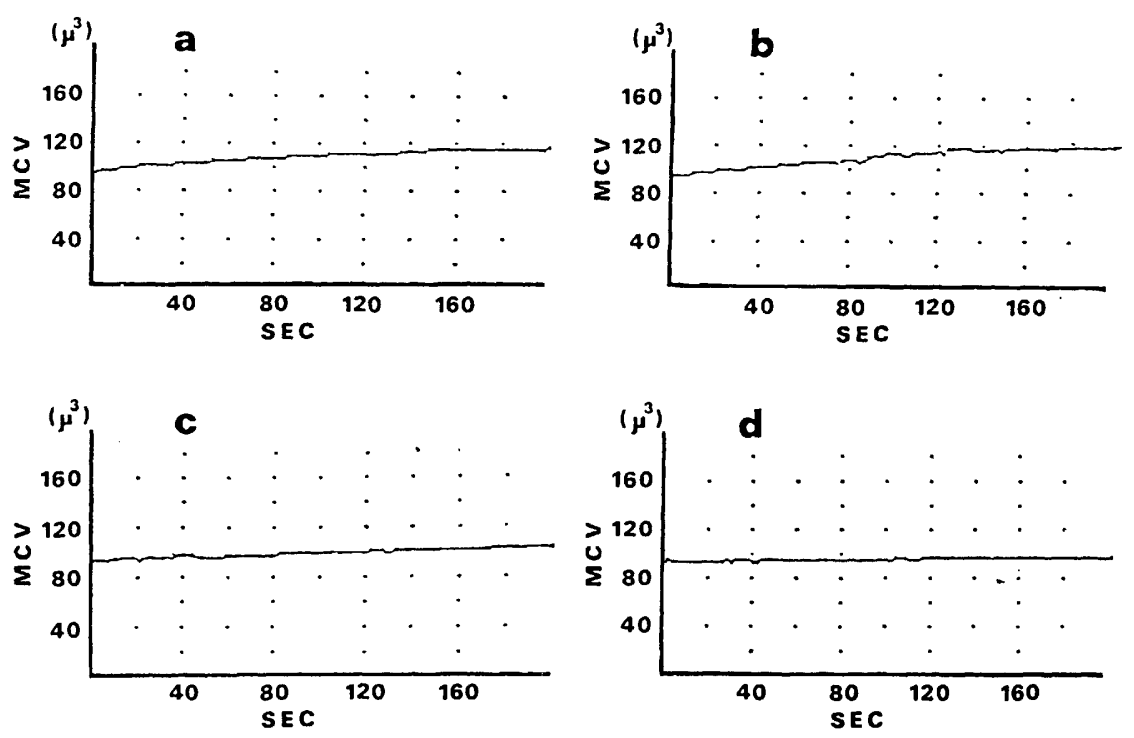

Fig. 3. MCV changes of erythrocytes in the mixture $(3: 2)$ of saline and various hexose solutions, such as galactose (a), mannose (b), glucose (c), and fructose (d). Final concentrations of hexoses are $0.11 \mathrm{M}$.

detect even slight changes in volume in a glycerol mixture, though in cases of urea, methanol, and ethanol the changes were so rapid that the analyzer responded poorly.

\section{Volume changes of erythrocytes in isotonic hexose solutions}

When erythrocytes were added to a mixture of isotonic hexose solutions and saline, the cell volume increased slowly to an equilibrated level. The patterns of volume increase were similar among various permeable hexoses, but the rate of volume increase $\left\{\right.$ (expanded volume-initial volume)/time; $\left.\mu \mathrm{m}^{3} / \mathrm{sec}\right\}$ and the expansion ratios (expanded volume/initial volume; $\mu \mathrm{m}^{3} / \mu \mathrm{m}^{3}$ ) differed with hexoses (Fig. 3). Table 1 shows the variation of expansion ratios obtained from the MCV curves. As indicated in the figures and the table, D-galactose showed a higher volume increase than the other hexoses. The order of the expansion ratio was D-galactose, D-glucose, D-mannose, D-fructose. Figure 4 shows the difference of volume increase rate between glucose and galactose from 2 to $20 \%$ of mixing ratios. The rate of volume increase revealed a dose-dependency.

\section{Comparison between the CMA method and other methods}

Two additional experiments were carried out using scanning electron microscopy and the microhematocrit method.

As shown in Fig. 5, erythrocytes in the galactose mixture were larger than in 
Table 1. Variation of expansion ratios in hexose solution. V0, V30, V60, $\mathrm{V} 120$, and V180 denote the volume $\left(\mu \mathrm{m}^{3}\right)$ at $0,30,60,120$, and $180 \mathrm{sec}$ after the start of the determination, respectively.

The mixing ratio of saline and isotonic hexose solution is 3 vol: 2 vol.

\begin{tabular}{lccccc}
\hline & & \multicolumn{4}{c}{ Expansion ratio } \\
\cline { 2 - 6 } & $N$ & V30/V0 & V60/V0 & V120/V0 & V180/V0 \\
\hline Galactose & 5 & $1.05 \pm 0.01$ & $1.08 \pm 0.02$ & $1.16 \pm 0.02$ & $1.20 \pm 0.01$ \\
Mannose & 5 & $1.05 \pm 0.01$ & $1.08 \pm 0.01$ & $1.15 \pm 0.02$ & $1.17 \pm 0.02^{*}$ \\
Glucose & 5 & $1.03 \pm 0.01$ & $1.07 \pm 0.01$ & $1.09 \pm 0.03^{*}$ & $1.12 \pm 0.02^{*}$ \\
Fructose & 5 & $1.01 \pm 0.01^{*}$ & $1.02 \pm 0.01^{*}$ & $1.02 \pm 0.01^{*}$ & $1.04 \pm 0.02^{*}$ \\
\hline
\end{tabular}

* Significantly different $(p<0.05)$ from the ratio of corresponded galactose values.

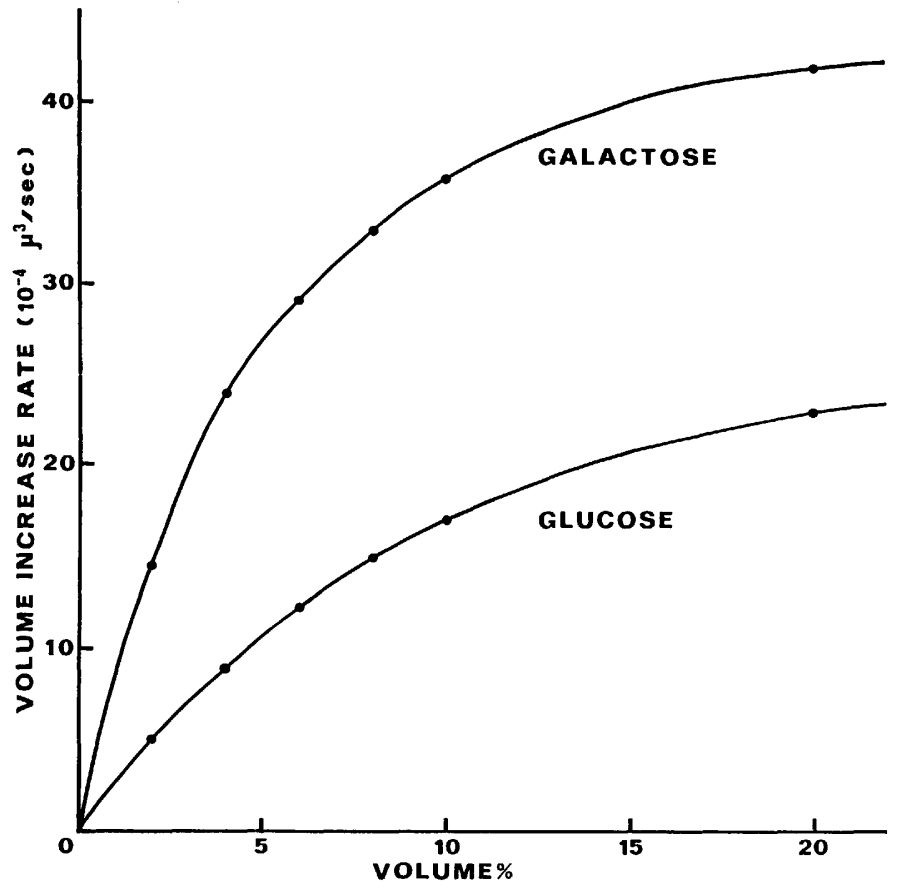

Fig. 4. Changes of volume increase rate $v s$. hexose (glucose and galactose) concentrations. Abscissa: volume \% of isotonic hexose solution in suspending media (saline and hexose solution). Ordinate: volume increase rate $\left(10 \mu \mathrm{m}^{3} / \mathrm{sec}\right)$ at $10 \mathrm{sec}$ after the start of the measurements.

the glucose mixture after a definite incubation time.

Figure 6 shows a comparison of the volume changes measured by the CMA method and by the hematocrit method in a galactose or a glucose mixture among 5 different samples. The cells in a galactose mixture showed a higher volume increase than those in a glucose mixture. However, the results obtained by CMA 


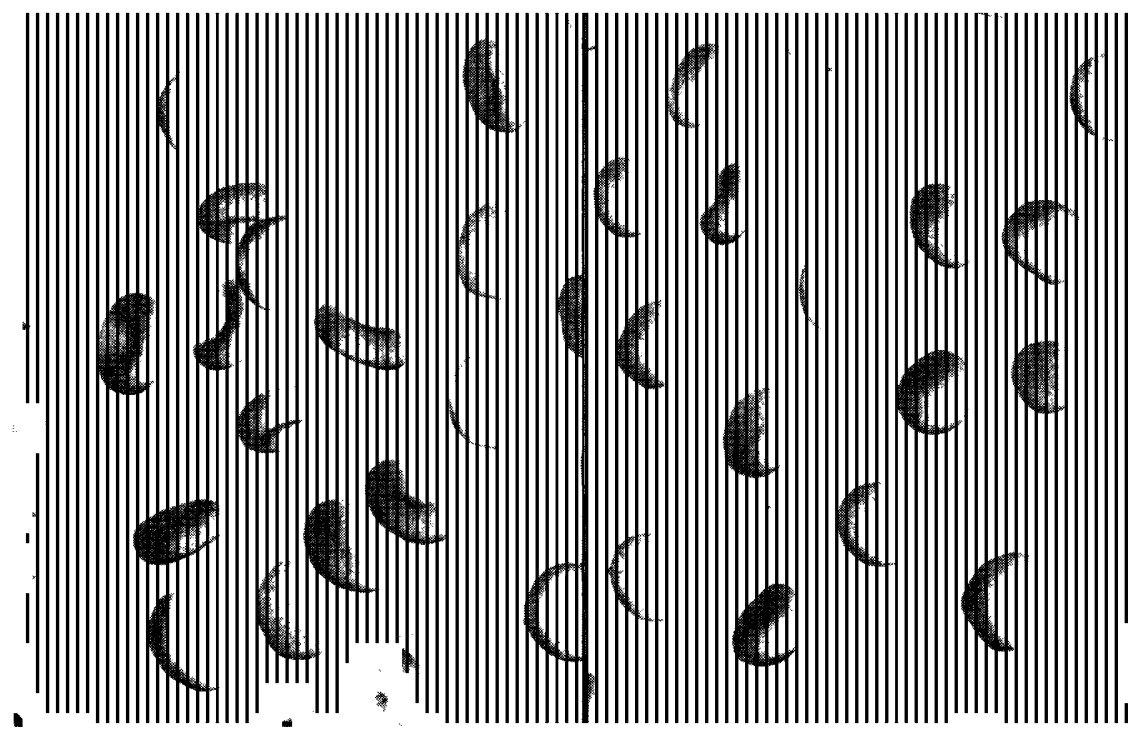

Fig. 5. Phase-contrast micrographs of erythrocytes after a 10-min suspension in a mixture (3:2) of saline and glucose (left) or galactose (right) solutions.

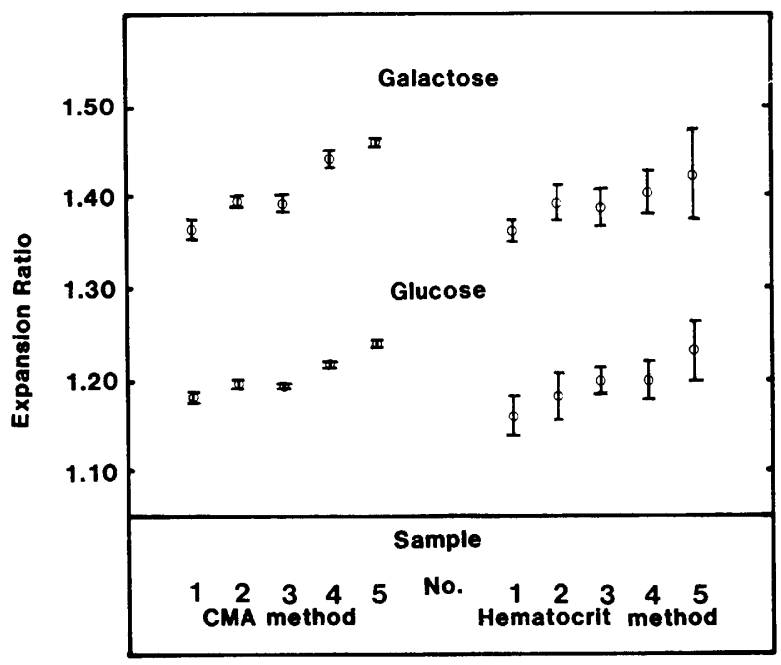

Fig. 6. Comparison of expansion ratios measured by CMA (left half) and microhematocrit method (right half) in 5 samples. Each point shows mean (open circle) \pm 1 S.D. (bar) in 5 determinations. The ratios of galactose (upper half) and glucose (lower half) are calculated at $10 \mathrm{~min}$ after the start of the measurements.

corresponded well to the data obtained by electron microscopy or the hematocrit method. Compared with our method, the hematocrit method has several technical problems such as difficulty in reading due to preexisting hemolysis, jaundice, 
hemoglobin leakage during the test, and irregular border formation due to incorrect setting of the capillary tube. Thus, the determined values showed higher variation in the hematocrit method than in the MCV method.

\section{DISCUSSION}

Coulter's principle is generally considered to provide high precision and reliability for measuring erythrocyte volume. However, conventional laboratory blood cell counters provide information on MCV under predetermined experimental conditions. On the contrary, continuous measurement of $\mathrm{MCV}$ can show small changes in cell volume with high precision and high stability, since continuous aspiration of cell suspension can minimize occurrence of turbulent flow around the aperture of the cell counter. Moreover, the CMA is designed to be able to correct changes in resistivity which depend on the conductivity of cell suspending medium. The idea of continuous measurement was first reported by us (TATSUMI, 1981) and physiological studies on the blood cells have since been carried out in several laboratories.

Regulation of cell volume is a functional expression of living cell membrane. Even in an isotonic state, permeable substances can pass through the erythrocyte membrane along the gradient of their concentration, resulting in volume increase (CORI, 1931; Bowyer, 1967; Macknight and Leaf, 1977). A practical example is a hemolysis test for hereditary spherocytosis cells and thalassemia cells which is usually carried out in an isotonic glycerol solution (POSTERARO and GOTTFRIED, 1978). In the case of glucose, UesaKa and Shinagawa (1979) also discussed the volume increase of erythrocytes incubated in an isotonic glucose solution. Thus, the volume increase shown by CMA in the isotonic mixture of saline and permeable substances could be considered a result of the transmembrane movement of the permeable substances. Electronmicroscopic and hematocrit findings would support this consideration.

Electronmicrographycally, erythrocytes incubated in an isotonic hexose solution and saline did not show echinocytic or stomatocytic transformation, but revealed an equally-swollen form. The findings refuted the concept that the swelling resulted from ATP depletion (BESSIS, 1974). Furthermore, the time required for swelling was short, thus the changes were caused not by metabolic inhibition but by increased permeability, as Macknight and Leaf stated (MACKNIGHT and LeAF, 1977).

The dose-dependent volume changes induced by glucose as determined by CMA corresponded well to those determined by the hematocrit method (UESAKA and Shinagawa, 1979). However, our data obtained by the hematocrit method showed obviously higher variations as compared to those by the CMA method. Hence, CMA method might be useful for the measurement of membrane permeability. Kinetic study of membrane permeability of various permeable sub- 
stances is in progress.

We thank Prof. Dr. S. Matsuura of Osaka City University for his helpful comments during this study.

\section{REFERENCES}

Archer, R. K., Coster, J. F., Crosland-Taylor, P. J., and England, J. M. (1982) International committee for standarization in hematology (ICSH): Selected method for the determination of packed cell volume. In: Advances in Hematological Methods: The Blood Count. 1st ed., ed. by Van Asseendelft, O. W. and England, J. M. CRC Press Inc., Florida, pp. 93-98.

Bessis, M. (1974) Corpuscles: Atlas of red blood cell shapes, Springer-Verlag, Berlin, Hidelberg, and New York, pp. 22-34.

BOWYER, F. (1967) The kinetics of the permeation of nonelectrolytes into the mammalian erythrocyte. Int. Rev. Cytol., 6, 469-511.

Cori, C. F. (1931) Mammalian carbohydrate metabolism. Physiol. Rev., 11: 143-275.

De Gier, E., Van Deenen, L. L. M., and Van Senden, K. G. (1966) Glycerol permeability of erythrocytes. Experientia, 22, 20-21.

ECKHOFF, R. K. (1969) A static investigation of the Coulter principle of particle sizing. J. Sci. Instrum., 2, 973-977.

GotTfried, E. L. and Robertson, N. A. (1972) RBC glycerol lysis time as a clinical tool. Blood, 40, 940 (Abstr.).

Hattori, A., Itoh, S., Sugawara, A., and Matsuoka, M. (1975) Studies on fixation and drying of blood cells for scanning electron microscopic observation. Acta Haematol. Jpn., 38: 8695 (in Japanese).

Levine, M. and SteIN, W. D. (1966) The kinetic parameters of the monosaccharide transfer system of the human erythrocyte. Biochim. Biophys. Acta, 127, 179-193.

Macknight, A. D. and Leaf, A. (1977) Regulation of cellular volume. Physiol. Rev., 57, 510573.

Mattern, C. F. T., Brackett, F. S., and Olson, B. J. (1957) Determination of number and size of particles by electrical gating: Blood cells. J. Appl. Physiol., 10: 56-70.

PARPART, A. K. (1935) The permeability of the mammalian erythrocyte to deutrium oxide (heavy water). J. Cell. Comp. Physiol., 7: 153-162.

Posteraro, A. and GotTrRied, E. L. (1978) The diagnostic significance of a prolonged erythrocytic glycerol lysis test (GLT 50). Am. J. Clin. Pathol., 70: 637-642.

Tatsumi, N. (1981) The size of erythrocyte ghosts. Biochim. Biophys. Acta, 641: 276-280.

Tatsumi, N., Maeda, H., IM, T., Wada, Y., Hayashi, M., and Kimura, E. (1981) A new method of red cell fragility test. Acta Haematol. Jpn., 44, 16-23.

Uesaka, N. and Shinagawa, K. (1979) Structure and physiological functions of erythrocyte: Hemolysis phenomenon and membrane permeability. Nihon Rinsho, 37: 3845-3852 (in Japanese).

Wessels, J. M. C. and Veerkamp, J. H. (1973) Some aspects of the osmotic lysis of erythrocytes. III. Comparison of glycerol permeability and lipid composition of red blood cell membranes from eight mammalian species. Biochim. Biophys. Acta, 291: 190-196.

ZIPPER, H. and MAWE, R. C. (1974) The exchange and maximal net flux of glucose across the human erythrocyte. II. The effect of two sulphydryl enzyme inhibitors, chlormerodrin and p-chloromercuribenzene sulfonic acid. Biochim. Biophys. Acta, 356: 207-218. 